\title{
A Method for the Simultaneous Determination of Chlorogenic Acid and Sesquiterpene Lactone Content in Industrial Chicory Root Foodstuffs
}

\author{
Honorine Willeman, ${ }^{1}$ Philippe Hance, ${ }^{1}$ Anne Fertin, ${ }^{2}$ Najia Voedts, ${ }^{1}$ Nathalie Duhal, ${ }^{3}$ \\ Jean-François Goossens, ${ }^{3}$ and Jean-Louis Hilbert ${ }^{1}$ \\ ${ }^{1}$ UMR 1281, Stress Abiotiques et Différenciation des Végétaux Cultivés, GIS GENOCHIC, INRA, IFR147, \\ Université Lille 1 Sciences et Technologies, Cité Scientifique, 59655 Villeneuve d'Ascq, France \\ ${ }^{2} I U T$ A, Département Génie Biologique, Université Lille 1 Sciences et Technologies, 59655 Villeneuve d’Ascq, France \\ ${ }^{3}$ Faculté des Sciences Pharmaceutiques et Biologiques, Centre Universitaire de Mesures et d'Analyses (CUMA), Université Lille 2, \\ BP 83, 3 rue du Pr. Laguesse, 59006 Lille Cedex, France \\ Correspondence should be addressed to Jean-Louis Hilbert; jean-louis.hilbert@univ-lillel.fr
}

Received 16 July 2014; Accepted 3 October 2014; Published 4 December 2014

Academic Editor: Thomas Efferth

Copyright (c) 2014 Honorine Willeman et al. This is an open access article distributed under the Creative Commons Attribution License, which permits unrestricted use, distribution, and reproduction in any medium, provided the original work is properly cited.

\begin{abstract}
A method for the simultaneous determination of free chlorogenic acids (CGA) and sesquiterpene lactones (STL) in chicory root and its dried (flour) and roasted (grain) forms is described. The method uses one extraction and one analysis for all chicory root products. Various solvents with low to high polarity, such as methanol, chloroform, or $n$-hexane, were tested alone, in combination in different proportions or with acidified or neutral aqueous solvent. The water/chloroform/methanol (30/30/40, v/v/v) mixture generated the best extraction yield, 21\% higher than alcohol mixtures. The profiling of CGA and STL content was performed through a conventional HPLC-DAD method using a PFP core shell column in a fast single run. Good retention time and area repeatability (RDD mean \% 0.46 and 5.6, resp.) and linearity $\left(R^{2} \geq 0.96\right)$ were obtained. The STL and chlorogenic acids levels determined were 254.7 and $100.2 \mu \mathrm{g} / \mathrm{g}$ of dry matter in the root, 792.5 and $1,547 \mu \mathrm{g} / \mathrm{g}$ in flour, and 160.4 and $822.5 \mu \mathrm{g} / \mathrm{g}$ in the roasted grains, respectively. With an average recovery of $106 \%$ and precision of $90 \%$, this method is rapid, reproducible, and straightforward way to quantify the chlorogenic acids and STL in chicory raw material and end products.
\end{abstract}

\section{Introduction}

Sesquiterpene lactones (STL) and chlorogenic acids (CGA) are soluble secondary main metabolites that accumulate in Asteraceae, especially in chicory [1]. The diversity of the chemical structure of these compounds allows these molecules to be involved in various physiological processes used by plants, such as the attraction of pollinators [2], the repulsion of herbivores [3], and protection against pathogens [4].

Many cultivated types of chicory (Cichorium intybus L.) exist, such as those used in salads, forage, and, in particular, industrial chicory utilized for the production of roots as raw material. Industrial chicory (Cichorium intybus var. sativum) has economic importance in many agricultural regions in the world as a source of inulin or food [5]. In northern France, chicory root is grown especially for use as dried or roasted products and beverage. Once harvested, the root is sliced and dried to produce an intermediate raw material called green slices. The slices are either ground to obtain flour or roasted and then crushed into grains. The grains can be marketed directly or extracted with hot water to obtain a concentrated liquid or, after spray-drying, soluble powders. Chicory flour can be used as bread-improving ingredient, and when roasted, chicory is used to enhance the aroma, color, or flavor of food. Thus, chicory root is consumed in different forms of derivative products in the human diet. 
In addition to their known roles in plants, secondary metabolites present in chicory root may add value to food products via their biological properties. STL and CGA are known for their anti-inflammatory [6], analgesic [7], and neuroprotective actions [8]. 3,5-Di-O-caffeoylquinic acid, a chlorogenic acid, is responsible for nearly $70 \%$ of the antioxidant activity of chicory [9]. In addition to their potential beneficial effects on human health, these secondary metabolites play a role in the organoleptic properties of chicory. Indeed, chicory root is known for its bitter taste, which is essentially due to STL, mainly lactucin (Lc) and lactucopicrin (Lp) $[10,11]$.

Taken together, these nutritional and organoleptic properties are important factors for the appreciation and consumption of chicory products. The contents of STL and CGA represent a quality parameter of the raw material. Characterizing these compounds is part of a broader framework of varietal improvement and process optimization programs designed to improve the end product quality. However, these approaches are constrained by the requirement for the often tedious extraction of several thousand samples, routine analysis, and multiple assays to ensure the detection of these molecular families in various matrices.

The composition and distribution of STL and CGA have been extensively studied in leaf products of chicory crops such as salads, chicon, and forage [12-14]. However, despite studies of these compounds in fresh or roasted roots $[11,15,16]$, the contents of both free STL and CGA in industrial chicory root and its derivative foods have not been determined.

Extraction modalities differ from one group of molecules to another and depend on the plant material from which the molecules are extracted. From the leaf of Cichorium intybus L. var. sylvestre, Mulinacci et al. [17] extracted CGA using water and fractionation by many solvents (ethanol, $n$ hexane, chloroform, and ethyl acetate). Price et al. [10] used methanol and chloroform to extract STL from the leaf of Cichorium intybus L. var. foliosum and var. sylvestre. Van Beek et al. [11] used ethyl acetate, methanol, chloroform, ethanol, and acetone sequentially to extract STL from the root of Cichorium intybus. More recently, the extraction of STL and CGA from "Catalogna and Head Radicchio" chicory leaves using a unique mixture of solvents was proposed [18] with separate analyses for the STL and CGA by high-performance liquid chromatography coupled to a diode array detector (HPLC-DAD).

Until now, no method for determining the major secondary metabolites involved in the qualities of the chicory root and processed products from this plant has been described. The purpose of this study was the development and validation of a method for the simultaneous determination of free STL and CGA from the root of Cichorium intybus var. sativum and its food products, including extraction and analysis. In our work, we tested different solvents and combinations of solvents to extract these major secondary metabolites from several matrices. We also developed a quantitative analytic method on conventional HPLC-DAD and a polar reverse-phase column Kinetex PFP for the rapid and selflimiting separation of target compounds. Compounds were authenticated by ultraperformance liquid chromatography coupled with high resolution mass spectrometer (UPLCHRMS).

\section{Methods}

2.1. Biological Materials. Three major transformation products of industrial chicory were analyzed. The root was obtained from an agronomic trial, located in Coutiches, France, conducted in 2011 by the company Florimond-Desprez Veuve et Fils SAS (Capelle-en-Pévèle, France). Flour and roasted grains were obtained from the company Leroux SAS (Orchies, France).

The samples were immediately frozen in liquid nitrogen and stored at $-80^{\circ} \mathrm{C}$. For the experiments, the samples were freeze-dried ( $48 \mathrm{~h}$ ) and ground (ball mill, Retsch, Eragny sur Oise, France) using $50 \mathrm{~mL}$ wells and $25 \mathrm{~mm}$ balls to obtain a fine powder. These samples were stored at $-80^{\circ} \mathrm{C}$.

2.2. Analytical Reagents and Chemicals. The solvents (methanol $(\mathrm{MeOH})$, ethanol (EtOH), chloroform $\left(\mathrm{CHCl}_{3}\right)$, dichloromethane $\left(\mathrm{CH}_{2} \mathrm{Cl}_{2}\right)$, acetonitrile (ACN), acetone (Ac), ethyl acetate (EtOAc), and $n$-hexane ( $n$-hex)), acetic acid (AAC), formic acid (FA), and ortho-phosphoric acid used for the extraction and chemical analysis were all HPLC grade and were obtained from the Dislab company (Lens, France). All of these solvents and acids were stored at $4^{\circ} \mathrm{C}$. The standards used for the HPLC analysis were 5-mono-O-caffeoylquinic acid (5-CQA) and 3,5-di-O-caffeoylquinic acid (3,5-diCQA) and were provided by Biopurify (Chengdu, China). 11(S),13Dihydrolactucin (DHLc), lactucin (Lc), 11(S),13-dihydrolactucopicrin (DHLp), and lactucopicrin (Lp) were provided by Extrasynthèse (Genay, France); 11(S),13-dihydro-8-deoxylactucin (DHdLc) and 8-deoxylactucin (dLc) were extracted, purified in the laboratory from industrial chicory root, and authenticated by ${ }^{1} \mathrm{H}$ nuclear magnetic resonance (NMR) and ${ }^{13}$ C NMR [19] (Figure 1).

2.3. Extraction of CGA and STL. Several extraction methods have been tested using different solvents and combinations to extract CGA and STL simultaneously, including methanol $100 \%(\mathrm{MeOH})$; ethanol 100\% (EtOH); acetone 100\% (Ac); ethyl acetate $100 \%$ (EtOAc); $n$-hexane $100 \%$ ( $n$-hex); chloroform $100 \%\left(\mathrm{CHCl}_{3}\right)$; dichloromethane $100 \%\left(\mathrm{CH}_{2} \mathrm{Cl}_{2}\right) ; 25 / 75$, $50 / 50$, and $75 / 25$ mixtures $(\mathrm{v} / \mathrm{v})$ of water/methanol $\left(\mathrm{H}_{2} \mathrm{O} /\right.$ $\mathrm{MeOH})$, water/chloroform $\left(\mathrm{H}_{2} \mathrm{O} / \mathrm{CHCl}_{3}\right)$, and water/ethanol $\left(\mathrm{H}_{2} \mathrm{O} / \mathrm{EtOH}\right) ; 75 / 24 / 1,75 / 23 / 2,75 / 22 / 3$, and $75 / 21 / 4$ mixtures (v/v/v) of methanol/water/acetic acid $\left(\mathrm{MeOH} / \mathrm{H}_{2} \mathrm{O} / \mathrm{AAC}\right)$ and methanol/water/formic acid $\left(\mathrm{MeOH} / \mathrm{H}_{2} \mathrm{O} / \mathrm{FA}\right)$; and $40 /$ $40 / 20,30 / 30 / 40,25 / 25 / 50$, and 20/20/60 mixtures (v/v/v) of water/chloroform/methanol $\left(\mathrm{H}_{2} \mathrm{O} / \mathrm{CHCl}_{3} / \mathrm{MeOH}\right)$. These extractions were carried out by maceration; $100 \mathrm{mg}$ powder was extracted with $1.5 \mathrm{~mL}$ of solvent (1/15 ratio, w/v). For the extraction modalities with water/chloroform and water/chloroform/methanol, the solvents were added one at a time. The tubes were agitated for $17 \mathrm{~h}(\mathrm{o} / \mathrm{n})$ in the dark at room temperature. The tubes were then centrifuged (12,000 r.p.m. at $4^{\circ} \mathrm{C}$ for $8 \mathrm{~min}$ ), and the supernatants were filtered in 96-well 
<smiles>[Y]C1CC(C)=C2C(=O)C=C(CO)C2C2OC(=O)C([Tl])C12</smiles>
(1) $\mathrm{R}^{1}=\mathrm{OH}$
$\mathrm{R}^{2}=\mathrm{CH}_{2}$
$\log P=-0.7$
$\mathrm{SP}=83$
(2) $\mathrm{R}^{1}=\mathrm{H}$
$\mathrm{R}^{2}=\mathrm{CH}_{2}$
$\log P=0.208$
$\mathrm{SP}=63.6$
(3) $\mathrm{R}^{1}=\mathrm{O}_{2} \mathrm{CCH}_{2} \mathrm{PhOH}$
$\mathrm{R}^{2}=\mathrm{CH}_{2}$
$\log P=1.1$
$\mathrm{SP}=110$
(4) $\mathrm{R}^{1}=\mathrm{OH}$
$\mathrm{R}^{2}=\mathrm{CH}_{3}$
$\log P=-0.54$
$\mathrm{SP}=83$
(5) $\mathrm{R}^{1}=\mathrm{H}$
$\mathrm{R}^{2}=\mathrm{CH}_{3}$
$\log P=0.37$
$\mathrm{SP}=63.6$
(6) $\mathrm{R}^{1}=\mathrm{O}_{2} \mathrm{CCH}_{2} \mathrm{PhOH}$
$\mathrm{R}^{2}=\mathrm{CH}_{3}$
$\log P=1.27$
$\mathrm{SP}=110$

(7) $\log P=1.5 \quad \mathrm{SP}=200$<smiles>O=C(/C=C/c1ccc(O)c(O)c1)O[C@H]1C[C@](O)(CCO)C[C@H]1OC(=O)/C=C/c1ccc(O)c(O)c1</smiles><smiles>O=C(O)C[C@@]12C[C@@H](OC(=O)/C=C/c3ccc(O)c(O)c3)[C@H](O)[C@@H](O)C1O2</smiles>

FIGURE 1: Structure, $\log P$ values, and surface polarity (SP) of the six sesquiterpene lactones: lactucin (1), 8-deoxylactucin (2), lactucopicrin (3), 11(S),13-dihydrolactucin (4), 11(S),13-dihydro-8-deoxylactucin (5), 11(S), 13-dihydrolactucopicrin (6), and two chlorogenic acids: 3,5-di$\mathrm{O}$-caffeoylquinic acid (7) and 5-mono-O-caffeoylquinic acid (8) identified in chicory roots products.

microplates (Pall GHP $0.45 \mu \mathrm{m}$, VWR, Fontenay-sous-Bois, France) and then analyzed by HPLC-DAD. Each extraction method was repeated three times. The $\mathrm{H}_{2} \mathrm{O} / \mathrm{CHCl}_{3}$ and $\mathrm{H}_{2} \mathrm{O} / \mathrm{CHCl}_{3} / \mathrm{MeOH}$ systems were immiscible, but adding $500 \mu \mathrm{L}$ of $\mathrm{MeOH}$ allowed for the phases mixing.

2.4. HPLC-DAD Quantification. A Prominence HPLC system (Shimadzu, Marne la Vallée, France) consisting of a quaternary pump (LC-20AD) and a UV-visible diode array detector (SPD-20A) was used to detect CGA and STL at 320 and $254 \mathrm{~nm}$, respectively. A Kinetex PFP column $(100 \times$ $4.6 \mathrm{~mm}, 2.6 \mu \mathrm{m}$ ) (Phenomenex, Le Pecq, France) was used for compound separation. The separation method lasted 16.5 $\mathrm{min}$. The elution was performed in gradient mode using three different solvents-water (solvent $\mathrm{A}$ ), $\mathrm{MeOH}$ (solvent $\mathrm{B}$ ), and ACN (solvent C) - all acidified with $0.1 \%$ ortho-phosphoric acid. Solvent B gradient rose from an initial $7.5-17.5 \%$ at $1 \mathrm{~min}, 32.5 \%$ at $5 \mathrm{~min}$, and $80 \%$ at $8 \mathrm{~min}$, returning to $7.5 \%$ at 9 min until the end of the run; solvent $\mathrm{C}$ was kept at $12 \%$ throughout. The oven temperature was $45^{\circ} \mathrm{C}$, and the flow rate was $1.1 \mathrm{~mL} / \mathrm{min}$. The amount of sample injected was $5 \mu \mathrm{L}$.

The quantification was performed by external calibration using standards (5-CQA, 3,5-diCQA, DHLc, Lc, DHdLc, dLc DHLp, Lp.), each repeated five times. The respective calibration curves were constructed by linear regression plotting signal area versus compound concentration. The analytic precision was measured within and between days. Each extract was analyzed three times consecutively and three times on three different days.

2.5. UPLC-High Resolution MS Analysis/Authentication. Chromatographic separation was performed on an Accela UPLC system (Thermo Scientific) equipped with a Kinetex PFP column $(100 \times 4.6 \mathrm{~mm}$, particle size $2.6 \mu \mathrm{m}$; Phenomenex $)$. The elution was performed with the same HPLC-DAD gradient mode as described previously using water (solvent A), $\mathrm{MeOH}$ (solvent B), and ACN (solvent C), all acidified with $0.1 \%$ formic acid. The LC flow rate was $1 \mathrm{~mL} / \mathrm{min}$; the injection volume was $5 \mu \mathrm{L}$. The column oven temperature was $45^{\circ} \mathrm{C}$ and the sample tray temperature $4^{\circ} \mathrm{C}$.

Eluted compounds were detected in negative mode in full mass scan $(\mathrm{m} / z 120$ to 900$)$ using a Thermo Scientific Orbitrap Mass Spectrometer Q Exactive equipped with a heated electrospray ionization source (HESI-II). Instrument parameters were as follows: sheath gas 60 , auxiliary gas 20 (both arbitrary units), spray voltage $4 \mathrm{kV}$, capillary temperature $275^{\circ} \mathrm{C}$, capillary voltage $-60 \mathrm{~V}$, tube lens voltage $-135 \mathrm{~V}$, skimmer voltage $-20 \mathrm{~V}$, and source temperature $300^{\circ} \mathrm{C}$. 
Mass spectra were recorded at a resolution of 50,000 with an automatic gain control (AGC) target of 500,000 and a maximum injection time of $500 \mathrm{~ms}$.

\subsection{Validation Method}

2.6.1. Linearity, Limit of Detection (LOD), and Limit of Quantification (LOQ). Linearity was studied for each molecule. Using a series of seven dilutions, the standard concentrations ranged from 3.3 to $70,000 \mathrm{ng} / \mathrm{mL}$, and each was repeated five times.

The LOD and LOQ were determined for each molecule. All dilutions were analyzed by HPLC-DAD to determine the average concentration $(\mu)$ corresponding to the loss of signal detection and quantification (blank sample) for each of the three products. The LOD was defined by $\mu+3 \sigma$ and LOQ by $\mu+10 \sigma$, where $\sigma$ represents the standard deviation of the blank.

2.6.2. Precision and Specificity. Repeatability was evaluated for each product by six successive repetitions of the extraction method. Reproducibility was calculated for each product by three successive repetitions performed on different days. The coefficient of variation (\% respective standard deviations (RSD)) served as a measure of precision.

The specificity of the extraction method was evaluated by varying the proportions of solvents $\mathrm{H}_{2} \mathrm{O} / \mathrm{CHCl}_{3} / \mathrm{MeOH}$ plus and minus $4 \%$ compared to the optimal method.

2.6.3. Extractability and Recovery Rate Matrix Effect. The root, flour, and roasted grains were extracted using the optimum conditions according to the extraction method (see Section 2.3). Once all the supernatant was recovered, the pellet was reextracted under the conditions described above. Three repetitions were performed on each product. The extraction efficiency was the rate of extractable compounds (without reextraction) under the optimal modality and was measured as the ratio between the contents obtained during the first extraction $(E 1)$ and all contents (first extraction $(E 1)+$ reextraction $17 \mathrm{~h}(E 2))$. The extraction rate $(\mathrm{ER})$ is expressed as

$$
\mathrm{ER}=\left(\frac{E 1}{(E 1+E 2)}\right) \times 100
$$

The recovery rate was calculated by adding $0.075,0.15$, or $0.3 \mathrm{mM}$ of 5 -CQA; $0.0075,0.03$, or $0.075 \mathrm{mM}$ of 3,5-diCQA; or $0.007,0.014$, or $0.045 \mathrm{mM}$ of DHLc to the flour. Three replicates are performed by employing the optimum extraction modality. The recovery rate (RR) is the ratio between the measured content (MC) and the theoretical content (TC):

$$
\mathrm{RR}=\left(\frac{\mathrm{MC}}{\mathrm{TC}}\right) \times 100 .
$$

The effect of the extraction mixture on possible conversions of the chemical structures of the target compounds was evaluated by observing the variation in their content by HPLC-DAD analysis. Three representative target compounds
(5-CQA, 3,5-diCQA, and DHLc) were directly added individually in three different concentrations to the solvent mixture, in a chicory or "no-chicory matrix" (flour wheat). The extraction procedure was completed as described. The overlapping of chromatographic signals corresponding to the addition of the molecules was evaluated. No matrix effect was obtained when no interfering peak was present and when the linearity of the response was observed.

2.7. Statistics and Calculation. All extractions and analyses were performed in triplicate, except for linearity, which was repeated five times. Data are expressed as the means of individual repeats with the RSD of each extraction condition. Statistical analysis was performed using R 2.15.1 for Windows [20] and used to examine between-extract variation. When the Bartlett test was significant for homogeneity of variance, the extraction effect on metabolite levels was estimated by a one-way ANOVA, and mean separations were evaluated by pairwise comparison using Student's $t$-test. $\log P$ values (predicted lipophilicity) were calculated from online cheminformatics services provided by the Molinspiration Property Calculation Service (2013) [21].

\section{Results and Discussion}

3.1. Method Development. Several methods for extracting STL or CGA from the leaves of Cichorium intybus L. var. Catalogna and var. Rosso di Chioggia [18], var. sylvestre [17], and Cichorium endivia var. crispa [22] have been described. However, no method for the determination of STL and CGA exists for industrial chicory root and its derivatives. In our work, these compounds were determined in different products of chicory from a single extraction and analysis. The relative contents obtained from the extraction were evaluated by HPLC-DAD.

The first screen was performed using pure solvents that cover a wide range of polarity, including $\mathrm{MeOH}$, EtOH, Ac, EtOAc, $n$-hex, $\mathrm{CHCl}_{3}$, or $\mathrm{CH}_{2} \mathrm{Cl}_{2}$. Only the contents obtained from a selection of solvents (maximum extraction without excluding any metabolites) are shown in Table 1. Thus, the extraction efficiency of $\mathrm{MeOH}$ compared to EtOH or $\mathrm{CHCl}_{3}$ was, on average, 4.5 times higher for all products. In general, in terms of the quantity of STL and CGA extracted, methanol is more effective $(P$ value $<0.05)$ than the less polar solvents such as chloroform [23] and ethanol [24]. The other tested solvents, including acetone, ethyl acetate, $n$ hexane, and dichloromethane, delivered extraction yields up to 7 times lower than $\mathrm{MeOH}$. These data are confirmed by the work of Ferioli and D'Antuono [18], which demonstrated that the extraction of chicory salad with $\mathrm{MeOH}$ yields at least twice the STL of extraction with $\mathrm{EtOH}$, acetone, or ethyl acetate. Although molecules are mainly extracted with chloroform, ethanol, and methanol, the content increases with solvent polarity. The solubility of STL and CGA, such as Lc or 5-CQA, in the alcoholic solvents may be due to the high surface polarity notably induced by hydroxyl, carbonyl, and $\gamma$-lactone moieties. However, the presence of methyl, methylene, and phenyl groups provides a lipophilic character 


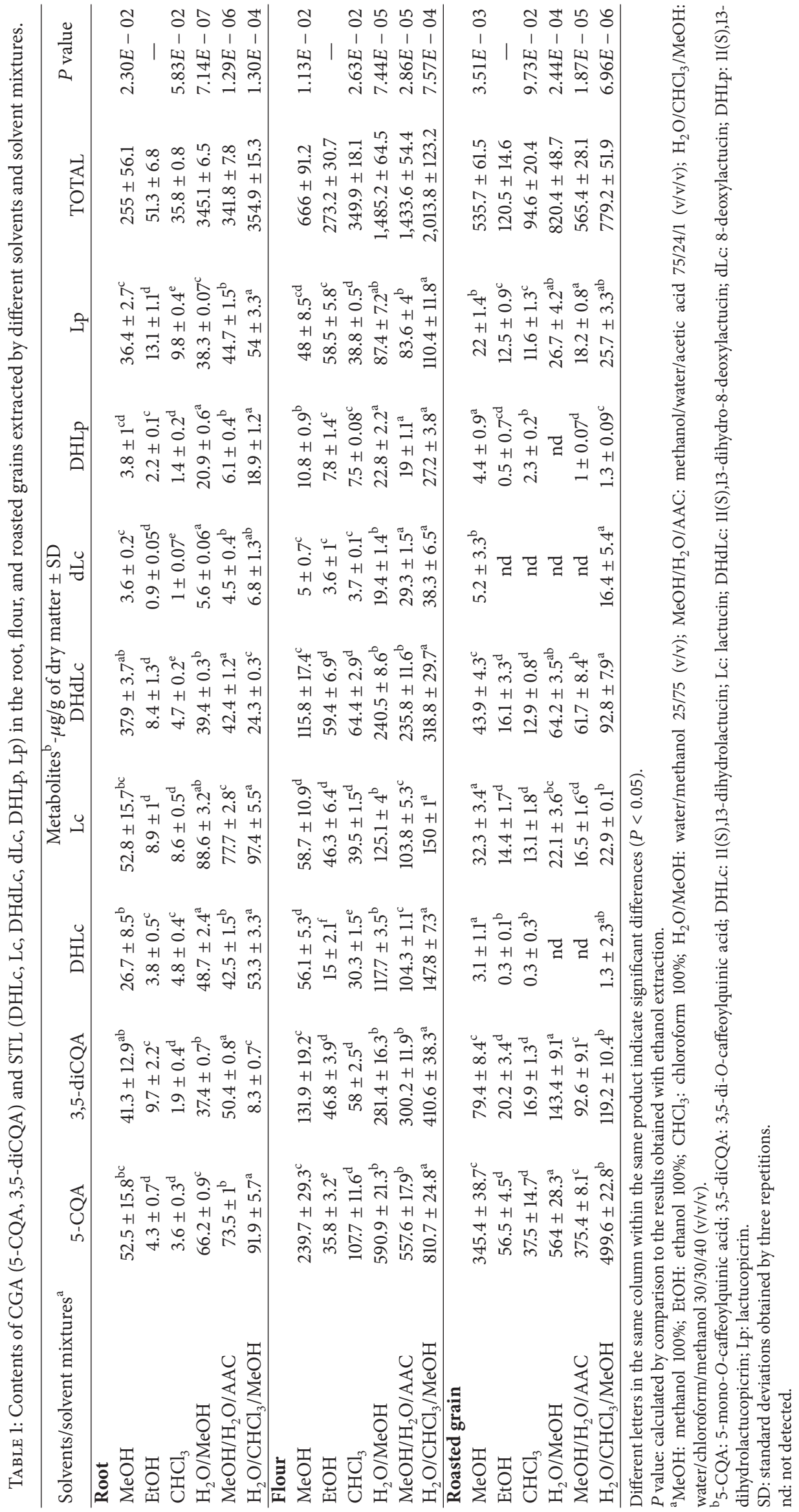


to the compounds that can explain their extractability in less polar solvents, such as chloroform. As observed with DHLp and Lp, their greater solubility in chloroform and in nonaqueous solvents, such as hexane or dichloromethane (data not shown), might be related to their higher lipophilicity shown by the calculated $\log P$ values of 1.27 and 1.1, respectively (Figure 1).

Extractability was increased by expanding the polarity range with the addition of water $(25,50$, or $75 \%)$ to three selected solvents. The aqueous alcohol system $\mathrm{H}_{2} \mathrm{O} / \mathrm{MeOH}$ $(25 / 75, \mathrm{v} / \mathrm{v})$ was more effective in extracting compounds with a low affinity for alcohol. Indeed, the addition of water increased the extraction efficiency of $\mathrm{MeOH}$ by 1.4 , 1.5, and 2.2 times for the root, roasted grains, and flour, respectively (Table 1 ). The water simultaneously reduced the dehydrating effect of $\mathrm{MeOH}$ and promoted its diffusion in the matrix, allowing a better penetration of the solvent mixture and an increased extraction of STL. These actions help to solubilize all target compounds more extensively. However, the effect was limited and resulted in a loss of performance when the percentages of water reached 50 and $75 \%$. Indeed, according to Elliott et al. [25], the swelling of the membranes favors the penetration of alcohol and is optimal when the proportion of water in the aqueous alcohol mixture is $25 \%$. These results are confirmed by Song et al. [24], who found that a porous membrane is favored by a high concentration of alcohol. Under the same conditions, the water was tested in combination with $\mathrm{CHCl}_{3}$ or $\mathrm{EtOH}$. As in the case of $\mathrm{MeOH}$, the best extraction rates were achieved with $25 \%$ water. Whereas a mixture of water and ethanol did not improve the extraction efficiency of the $\mathrm{H}_{2} \mathrm{O} / \mathrm{MeOH}$ system $(25 / 75, \mathrm{v} / \mathrm{v})$, adding water to $\mathrm{CHCl}_{3}$ increased the extraction rate of the roasted product and root by 2- and 3fold, respectively. Chloroform, which is less polar than water, carries more amphiphilic-like and fewer polar compounds. According to Burianek and Yousef [26], the interface between these two solvents, which results from their immiscibility, forms a suitable environment to concentrate these molecules. Moreover, during maceration, agitation optimizes not only the transfer of matrix molecules to water but also water to this interface. Therefore, the molecules' affinity for less polar phases promotes their extraction in chloroform. To increase the extraction polarity, optimization was conducted using an $\mathrm{H}_{2} \mathrm{O} / \mathrm{MeOH}$ combination $(25 / 75, \mathrm{v} / \mathrm{v})$, which we denote as $\mathrm{H}_{2} \mathrm{O} / \mathrm{MeOH}$.

Organic acids are known to penetrate and destabilize agent membranes [27]. As such, acetic acid (AAC) and formic acid (FA) were tested in addition to the methanol mixture to maximize extraction. The $\mathrm{MeOH} / \mathrm{H}_{2} \mathrm{O} / \mathrm{AAC}$ system (75/24/1, $\mathrm{v} / \mathrm{v} / \mathrm{v}$ ) conferred the same extraction yields for the root and flour but up to 1.5 times lower than the $\mathrm{H}_{2} \mathrm{O} / \mathrm{MeOH}$ system for the roasted grains (Table 1). The final proportion of acid in the mixture $(2,3$, or $4 \%)$ or the use of formic acid instead of acetic acid did not cause a significant difference in the extraction yields of flour $(P$ value $=0.06)$ and roasted grains $(P$ value $=0.14)$. Furthermore, the superposition and similarity of the absorption spectra of target signals indicated no difference between an acidified extraction and a nonacidified extraction (data not shown).
The extraction method was optimized by combining water with chloroform and methanol in different proportions. The presence of chloroform in the mixture increased the extraction yield of the flour by $35 \%$ compared to $\mathrm{H}_{2} \mathrm{O} / \mathrm{MeOH}$ (Table 1). Chloroform, a solvent of intermediate polarity, leads to the generation of twice as many amphiphilic-like molecules as $\mathrm{H}_{2} \mathrm{O} / \mathrm{MeOH}$, similarly to dLc and 3,5-diCQA. The presence of methanol in the water and the interface between chloroform and the aqueous phase would extend the polarity of the mixture, facilitating the extraction of polar and less polar compounds. These compounds were then recovered together by removing the interface through the addition of methanol, allowing their simultaneous analysis.

3.2. Authentication. Main secondary metabolites of the chicory are authenticated in chicory products by UPLC-HRMS. Table 2 shows authentication characteristics of STL and CGA in flour. Theoretical exact mass (M) was calculated from the formula at which one proton is subtracted (M-H+) for negative mode analysis. Each molecular ion $(\mathrm{M}-\mathrm{H}+)$ was extracted from the MS-TIC (Total Ionic Courant).

Exact mass $(\mathrm{Mc})$, elementary formula, ring double bond (RDB), and precision (ppm) are calculated for each analyte. All elementary formula propositions with precision more than $7 \mathrm{ppm}$ are rejected. For flour, the lowest ppm is $4.156 \pm$ 0.260 for 3,5-diCQA and the highest is $6.658 \pm 0.160$ for DHLp, with an average of 5.866. When exact mass with exactly elementary formula and low ppm have the same RDB theoretical, we can authenticate the molecule. Each exact mass $(\mathrm{Mc})$ is associated with a retention time (RT) and elution order is the same as for the HPLC-DAD analysis.

All metabolites are authenticated in flour (Table 2) but also in root and roasting grains (data not shown).

\subsection{Validation}

3.3.1. $L O D, L O Q$, and Linearity. In this study, the following STL and CGA commonly found in chicory were studied: DHLc, Lc, DHdLc, dLc, DHLp, Lp, 5-CQA, and 3,5-diCQA. The quantification of target compounds was undertaken by an HPLC-DAD analysis of standards. For the efficient separation of all metabolites of interest while providing a meaningful flow analysis, we used chromatographic columns based on core-shell particles of $2.6 \mu \mathrm{m}$ [28]. A Kinetex PFP column (Phenomenex) was chosen because of its ability to separate positional isomers [29]. The samples analyzed showed separation with a very good resolution of the target compounds in $16.5 \mathrm{~min}$. This method allows for the analysis of approximately 90 samples per day operating in a conventional chromatographic system.

Table 3 shows the RT, the LOD and LOQ, the linearity range, the coefficient of determination $\left(R^{2}\right)$, and the equation of the slope of the standard range for each metabolite tested. The STL absorbed in UV range between 190 and $260 \mathrm{~nm}$ (max. $254 \mathrm{~nm}$ ) and the CGA between 210 and $320 \mathrm{~nm}$ (max. $320 \mathrm{~nm}$ ). The RTs of each molecule for all wavelengths were different, indicating the lack of coelution of molecules, as evidenced by the resolution factor Rs value above 8.5 
TABLE 2: Authentication of CGA and STL in chicory flour by negative-ion UPLC-HRMS analysis.

\begin{tabular}{lcccccc}
\hline Metabolites $^{\mathrm{a}}$ & Formula & $\begin{array}{c}\mathrm{M}-\mathrm{H}+ \\
\text { theoretical }\end{array}$ & RDB & $\begin{array}{c}\mathrm{RT} \\
\text { min }\end{array}$ & $\begin{array}{c}\mathrm{M}-\mathrm{H}+ \\
\text { average } \pm \text { SD }\end{array}$ & $\begin{array}{c}\text { Precision (ppm) } \\
\text { average } \pm \text { SD }\end{array}$ \\
\hline 5-CQA & $\mathrm{C}_{16} \mathrm{H}_{18} \mathrm{O}_{9}$ & 353.08726 & 8.5 & 1.85 & $353.08856 \pm 8.83 E-05$ & $5.244 \pm 0.250$ \\
DHLc & $\mathrm{C}_{15} \mathrm{H}_{18} \mathrm{O}_{5}$ & 277.10760 & 7.5 & 2.07 & $277.10884 \pm 3.74 E-05$ & $6.460 \pm 0.135$ \\
Lc & $\mathrm{C}_{15} \mathrm{H}_{16} \mathrm{O}_{5}$ & 275.09970 & 8.5 & 2.30 & $275.09316 \pm 5.10 E-05$ & $6.397 \pm 0.186$ \\
3,5-diCQA & $\mathrm{C}_{25} \mathrm{H}_{24} \mathrm{O}_{12}$ & 515.11895 & 14.5 & 3.65 & $515.12061 \pm 1.02 E-04$ & $4.156 \pm 0.260$ \\
DHdLc & $\mathrm{C}_{15} \mathrm{H}_{18} \mathrm{O}_{4}$ & 261.11260 & 7.5 & 4.04 & $261.11376 \pm 4.19 E-05$ & $6.209 \pm 0.160$ \\
dLc & $\mathrm{C}_{15} \mathrm{H}_{16} \mathrm{O}_{4}$ & 259.09700 & 8.5 & 4.04 & $259.09803 \pm 5.44 E-05$ & $6.000 \pm 0.197$ \\
DHLp & $\mathrm{C}_{23} \mathrm{H}_{24} \mathrm{O}_{7}$ & 411.14430 & 12.5 & 6.82 & $411.14657 \pm 6.60 E-05$ & $6.658 \pm 0.160$ \\
Lp & $\mathrm{C}_{23} \mathrm{H}_{22} \mathrm{O}_{7}$ & 409.12870 & 13.5 & 6.91 & $409.13055 \pm 2.46 E-04$ & $5.802 \pm 0.601$ \\
\hline
\end{tabular}

5-CQA: 5-mono-O-caffeoylquinic acid; DHLc: 11(S),13-dihydrolactucin; Lc: lactucin; 3,5-diCQA: 3,5-di-O-caffeoylquinic acid; DHdLc: 11(S),13-dihydro-8deoxylactucin; dLc: 8-deoxylactucin; DHLp: 11(S),13-dihydrolactucopicrin; Lp: lactucopicrin.

$\mathrm{M}-\mathrm{H}+$ : molecular weight without one hydrogen.

RDB: ring double bond.

RT: retention times.

SD: standard deviations obtained by three repetitions.

TABLE 3: Retention time (RT), limit of detection (LOD) and of quantitation (LOQ), linearity range, determination coefficient $\left(R^{2}\right)$, and regression equation of metabolites tested.

\begin{tabular}{|c|c|c|c|c|c|c|}
\hline Metabolites $^{\mathrm{a}}$ & $\begin{array}{c}\mathrm{RT} \\
\operatorname{avg} \pm \mathrm{SD}\end{array}$ & $\begin{array}{c}\text { LOD } \\
\mathrm{ng} / \mathrm{mL}\end{array}$ & $\begin{array}{c}\text { LOQ } \\
\mathrm{ng} / \mathrm{mL}\end{array}$ & $\begin{array}{c}\text { Linearity range } \\
\mathrm{ng} / \mathrm{mL}\end{array}$ & $R^{2}$ & Regression equation \\
\hline 5-CQA & $1.62 \pm 0.010$ & 8.1 & 8.5 & $8.5-42,000$ & 0.9993 & $y=1 E+07 x$ \\
\hline DHLc & $2.01 \pm 0.009$ & 2 & 5.7 & $5.7-35,000$ & 0.9930 & $y=4 E+07 x$ \\
\hline $\mathrm{Lc}$ & $2.29 \pm 0.007$ & 6.4 & 13.7 & $13.7-70,000$ & 0.9954 & $y=3 E+07 x$ \\
\hline 3,5-diCQA & $5.11 \pm 0.033$ & 9.3 & 66.5 & $66.5-62,000$ & 0.9986 & $y=2 E+07 x$ \\
\hline DHdLc & $5.41 \pm 0.023$ & 9.5 & 18.1 & $18.1-50,000$ & 0.9954 & $y=3 E+07 x$ \\
\hline dLc & $5.59 \pm 0.023$ & 4.1 & 11.4 & $11.4-10,000$ & 0.9903 & $y=6 E+07 x$ \\
\hline DHLp & $8.74 \pm 0.037$ & 2.5 & 3.3 & $3.3-2,000$ & 0.9645 & $y=4 E+07 x$ \\
\hline Lp & $8.88 \pm 0.041$ & 5.9 & 20.5 & $20.5-12,000$ & 0.9910 & $y=3 E+07 x$ \\
\hline
\end{tabular}

a 5-CQA: 5-mono-O-caffeoylquinic acid; DHLc: 11(S),13-dihydrolactucin; Lc: lactucin; 3,5-diCQA: 3,5-di-O-caffeoylquinic acid; DHdLc: 11(S),13-dihydro-8deoxylactucin; dLc: 8-deoxylactucin; DHLp: 11(S),13-dihydrolactucopicrin; Lp: lactucopicrin.

(i.e., DHLp and Lp), promoting better quantization. This separation is even more effective using the Kinetex column, whose chemistry (based on PFP groups, aromatic interaction $\pi-\pi$, and $\mathrm{H}-\mathrm{F}$ ) allows for the resolution of positional isomers, which include the targeted CGA and STL. The analytic precision (repeatability and reproducibility) was measured by the intra- and interday (three different days) repetition method and is expressed in terms of the variation (RSD \%) of RT and areas obtained (Table 4). A small variation of RT (here, a maximum of $0.9 \%$ ) is very important to avoid the misidentification of peaks in samples. The area variation was, in general, small but higher for the reproducibility tests, with means of $6.8 \%$ for CGA and $6.4 \%$ for STL, as summarized in Table 4.

The LODs defined for all compounds were between 2 and $9.5 \mathrm{ng} / \mathrm{mL}$ (Table 3). The LOQs ranged from 3.3 to $89.5 \mathrm{ng} / \mathrm{mL}$. Linearity ranges varied from 1 to 6,140 times the LOQ (Table 3). Thus, the concentration range, for all compounds, extended from 3.3 to $70,000 \mathrm{ng} / \mathrm{mL}$. Linearity was perfectly preserved for each range, as illustrated by $R^{2}$ above
0.96. For each molecule, the $\mathrm{H}_{2} \mathrm{O} / \mathrm{CHCl}_{3} / \mathrm{MeOH}$ system $(30 / 30 / 40, v / v / v)$ enables the extraction of a content greater than the limit of quantification without surpassing the limit of linearity. Under these extraction conditions, no additional preparation, such as dilution or enrichment, is necessary for these samples.

3.3.2. Precision and Specificity. The precision of the $\mathrm{H}_{2} \mathrm{O}$ / $\mathrm{CHCl}_{3} / \mathrm{MeOH}(30 / 30 / 40$, v/v/v) extraction method was evaluated by six successive intraday repetitions and three successive interday repetitions. This variable is expressed in terms of variation (RSD \%) by the repeatability and reproducibility of the obtained contents of each target metabolite (Table 4). A maximum of 10 and $12 \%$ variation was observed for repeatability and reproducibility, respectively. These results indicate good accuracy of the extraction for all target metabolites.

A variation of $\pm 4 \%$ in the ratio of the $\mathrm{H}_{2} \mathrm{O} / \mathrm{CHCl}_{3} / \mathrm{MeOH}$ solvents relative to the optimal modality $(30 / 30 / 40, \mathrm{v} / \mathrm{v} /$ v) introduces a variability of $\pm 20 \%$ from the average (data not shown). These results demonstrate the selectivity of 
TABLE 4: Extractability rate of the extraction $\mathrm{H}_{2} \mathrm{O} / \mathrm{CHCl}_{3} / \mathrm{MeOH} 30 / 30 / 40$ (v/v/v), repeatability, and reproducibility expressed in terms of the variation (RSD \%) of contents. The repeatability and reproducibility of the HPLC-DAD method are expressed in terms of the variation (RSD \%) of retention times (RT) and areas.

\begin{tabular}{|c|c|c|c|c|c|c|c|c|}
\hline & \multicolumn{8}{|c|}{ Metabolites $^{\mathrm{a}}$} \\
\hline & 5-CQA & 3,5-diCQA & DHLc & $\mathrm{Lc}$ & DHdLc & $\mathrm{dLc}$ & DHLp & $\mathrm{Lp}$ \\
\hline \multicolumn{9}{|l|}{ Extraction } \\
\hline \multicolumn{9}{|l|}{ Extractability rate \% } \\
\hline Root & 94 & 76 & 79 & 82 & 85 & 86 & 84 & 85 \\
\hline Flour & 82 & 82 & 85 & 84 & 85 & 84 & 85 & 85 \\
\hline Roasted grains & 86 & 85 & 88 & 89 & 89 & 87 & 89 & 89 \\
\hline \multicolumn{9}{|l|}{ Repeatability RSD \% } \\
\hline Root & \pm 4 & \pm 6 & \pm 2 & \pm 2 & \pm 7 & \pm 9 & \pm 6 & \pm 8 \\
\hline Flour & \pm 6 & \pm 5 & \pm 9 & \pm 7 & \pm 6 & \pm 7 & \pm 5 & \pm 7 \\
\hline Roasted grains & \pm 4 & \pm 4 & \pm 2 & \pm 10 & \pm 7 & \pm 5 & \pm 10 & \pm 4 \\
\hline \multicolumn{9}{|l|}{ Reproducibility RSD \% } \\
\hline Root & \pm 6 & \pm 6 & \pm 5 & \pm 4 & \pm 9 & \pm 11 & \pm 8 & \pm 8 \\
\hline Flour & \pm 5 & \pm 6 & \pm 7 & \pm 10 & \pm 7 & \pm 9 & \pm 7 & \pm 11 \\
\hline Roasted grains & \pm 6 & \pm 6 & \pm 9 & \pm 8 & \pm 11 & \pm 5 & \pm 12 & \pm 6 \\
\hline \multicolumn{9}{|l|}{ HPLC-DAD analysis } \\
\hline \multicolumn{9}{|l|}{ Repeatability } \\
\hline \multicolumn{9}{|l|}{ RT RSD \% } \\
\hline Root & \pm 0 & \pm 0.6 & \pm 0 & \pm 0 & \pm 0.3 & \pm 0.9 & \pm 0.6 & \pm 0.6 \\
\hline Flour & \pm 0.4 & \pm 0.6 & \pm 0.4 & \pm 0.4 & \pm 0.5 & \pm 0.9 & \pm 0.4 & \pm 0.3 \\
\hline Roasted grains & \pm 0.3 & \pm 0.6 & \pm 0.3 & \pm 0.3 & \pm 0.6 & \pm 0.8 & \pm 0.6 & \pm 0.7 \\
\hline \multicolumn{9}{|l|}{ Areas RSD \% } \\
\hline Root & \pm 5.1 & \pm 7.2 & \pm 5.7 & \pm 3.5 & \pm 9.7 & \pm 14.3 & \pm 11.3 & \pm 4.1 \\
\hline Flour & \pm 1.3 & \pm 1.6 & \pm 3.2 & \pm 2.9 & \pm 6.6 & \pm 12 & \pm 13.2 & \pm 6.6 \\
\hline Roasted grains & \pm 2.5 & \pm 4.1 & \pm 7.7 & \pm 1.1 & \pm 6.1 & \pm 3.3 & \pm 1.3 & \pm 1.1 \\
\hline \multicolumn{9}{|l|}{ Reproducibility } \\
\hline \multicolumn{9}{|l|}{ RT RSD \% } \\
\hline Root & \pm 0.6 & \pm 1.5 & \pm 1.0 & \pm 1.0 & \pm 1.0 & \pm 0.6 & \pm 1.5 & \pm 1.0 \\
\hline Flour & \pm 0.6 & \pm 0.6 & \pm 0 & \pm 0.6 & \pm 0.6 & \pm 1 & \pm 1.2 & \pm 0.6 \\
\hline Roasted grains & \pm 0.6 & \pm 1.0 & \pm 0 & \pm 1.0 & \pm 1.2 & \pm 0.6 & \pm 1.2 & \pm 1.5 \\
\hline \multicolumn{9}{|l|}{ Areas RSD \% } \\
\hline Root & \pm 11.5 & \pm 7.7 & \pm 2.7 & \pm 11.9 & \pm 8.3 & \pm 6.4 & \pm 10.5 & \pm 10.2 \\
\hline Flour & \pm 5.4 & \pm 3.6 & \pm 5.5 & \pm 3.6 & \pm 3.8 & \pm 9.5 & \pm 6.2 & \pm 4.9 \\
\hline Roasted grains & \pm 4.4 & \pm 5.8 & \pm 8.8 & \pm 3.3 & \pm 6.7 & \pm 8.4 & \pm 5.1 & \pm 1.8 \\
\hline
\end{tabular}

a-CQA: 5-mono-O-caffeoylquinic acid; 3,5-diCQA: 3,5-di-O-caffeoylquinic acid; DHLc: 11(S),13-dihydrolactucin; Lc: lactucin; DHdLc: 11(S),13-dihydro-8deoxylactucin; dLc: 8-deoxylactucin; DHLp: 11(S),13-dihydrolactucopicrin; Lp: lactucopicrin.

RSD: respective standard deviations.

the method and the importance of respecting the parameters set forth above.

3.3.3. Extractability, Recovery Rate, and Matrix Effect. The extraction efficiency of the ternary mixture $\mathrm{H}_{2} \mathrm{O} / \mathrm{CHCl}_{3}$ / $\mathrm{MeOH}(30 / 30 / 40, \mathrm{v} / \mathrm{v} / \mathrm{v})$ was evaluated for each metabolite in the three products (Table 4). Residual contents measured from the reextraction of the pellet were used to define the extractability rate of the first method. The minimum extractability was observed for 3,5-diCQA in root (76\%), and the maximum extractability was observed for the 5-CQA in the root $(94 \%)$. For all metabolites, only one extraction of $17 \mathrm{~h}$ yielded $84 \%$ total efficiency for the roots and flour and $88 \%$ for the roasted grains. Extractability is favorable for STL present in roasted matrix, as shown by a yield close to $89 \%$. However, the measured levels indicate a low initial concentration of STL in the roasted grains.

5-CQA, 3,5-diCQA, and DHLc were added to the flour at different concentrations to determine the recovery rate of the $\mathrm{H}_{2} \mathrm{O} / \mathrm{CHCl}_{3} / \mathrm{MeOH}(30 / 30 / 40$, v/v/v) extraction method. The flour was used because of its richness in STL and CGA. The concentrations tested were $0.075,0.15$, and $0.3 \mathrm{mM} \mathrm{5-}$ CQA; 0.0075, 0.03, and 0.075 mM 3,5-diCQA; and 0.007, 0.014 , and $0.045 \mathrm{mM}$ DHLc. Recovery rates were between 94 and $122 \%$ (Table 5), with an average rate of $106 \%$, indicating the effectiveness of the method. 


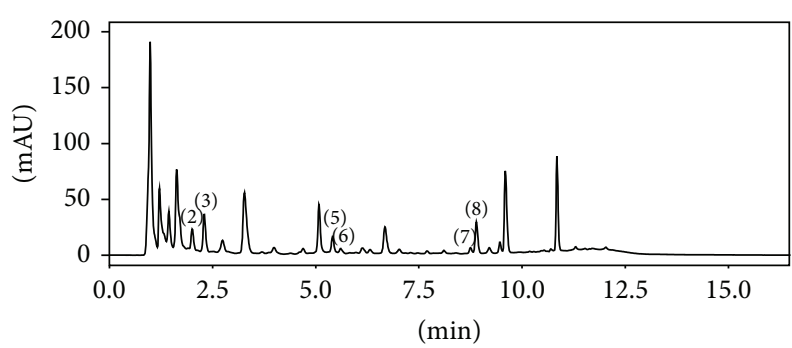

(a)

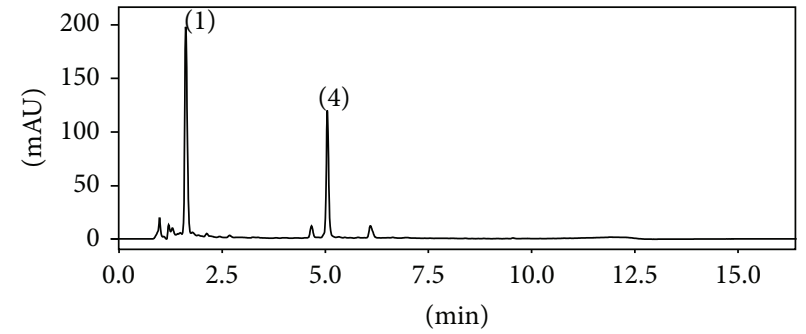

(b)

FIGURE 2: HPLC-DAD chromatograms of sesquiterpene lactones and chlorogenic acids in chicory root product (flour) obtained with $\mathrm{H}_{2} \mathrm{O} / \mathrm{CHCl}_{3} / \mathrm{MeOH} 30 / 30 / 30$ (v/v/v) extraction: (a) STL at $254 \mathrm{~nm}$ and (b) CGA at $320 \mathrm{~nm}$. (1) 5-Mono-O-caffeoylquinic acid, (2) 11(S),13dihydrolactucin, (3) lactucin, (4) 3,5-di-O-caffeoylquinic acid, (5) 11(S),13-dihydro-8-deoxylactucin, (6) 8-deoxylactucin, (7) 11(S), 13dihydrolactucopicrin, and (8) lactucopicrin.

TABLE 5: Recovery (\%) of the extraction of $\mathrm{H}_{2} \mathrm{O} / \mathrm{CHCl}_{3} / \mathrm{MeOH}$ 30/30/40 (v/v/v) with different additions (5-CQA, 3,5-diCQA, and DHLc) to flour.

\begin{tabular}{|c|c|c|c|}
\hline & \multicolumn{3}{|c|}{ Metabolites $^{\mathrm{a}}$} \\
\hline & 5-CQA & 3,5-diCQA & DHLc \\
\hline \multicolumn{4}{|l|}{ Add 5-CQA } \\
\hline $0.075 \mathrm{mM}$ & $96 \%$ & - & - \\
\hline $0.15 \mathrm{mM}$ & $97 \%$ & - & - \\
\hline $0.3 \mathrm{mM}$ & $94 \%$ & - & - \\
\hline \multicolumn{4}{|c|}{ Add 3,5-diCQA } \\
\hline $0.0075 \mathrm{mM}$ & - & $106 \%$ & - \\
\hline $0.03 \mathrm{mM}$ & - & $111 \%$ & - \\
\hline $0.075 \mathrm{mM}$ & - & $116 \%$ & - \\
\hline \multicolumn{4}{|l|}{ Add DHLc } \\
\hline $0.007 \mathrm{mM}$ & - & - & $106 \%$ \\
\hline $0.014 \mathrm{mM}$ & - & - & $103 \%$ \\
\hline $0.045 \mathrm{mM}$ & - & - & $122 \%$ \\
\hline
\end{tabular}

a-CQA: 5-mono-O-caffeoylquinic acid; 3,5-diCQA: 3,5-di-O-caffeoylquinic acid; DHLc: 11(S),13-dihydrolactucin.

The addition of different concentrations of 5-CQA, 3,5diCQA, and DHLc in a chicory (flour) and "no-chicory" (wheat flour) matrix was used to evaluate the effect of the $\mathrm{H}_{2} \mathrm{O} / \mathrm{CHCl}_{3} / \mathrm{MeOH}(30 / 30 / 40$, v/v/v) extraction mixture on the conversion of the chemical structure of the target compounds. The choice of "no-chicory" material focused on wheat flour because the targeted metabolites are absent. In the chicory matrix, the variation in the levels of metabolites, with or without addition, was between 2 and $9 \%$ and was included within the repeatability values. In the "no-chicory" matrix, no conversion was observed for the other molecules (contents), and the solvent alone did not change the structure of the compounds (data not shown).

3.4. STL and CGA in Products Derived from Chicory. The flour and the roasted product were derived from the same batch of roots and were analyzed with the evaluated determination method (Figure 2). For the first time, the CGA and STL composition was demonstrated in chicory flour and the presence of STL in the roasted grains was identified. The sesquiterpene lactones and chlorogenic acids levels were 254.7 and $100.2 \mu \mathrm{g} / \mathrm{g}$ of dry matter in the root, 792.5 and $1,547 \mu \mathrm{g} / \mathrm{g}$ in flour, and 160.4 and $822.5 \mu \mathrm{g} / \mathrm{g}$ in the roasted grains, respectively (Table 1 ). The ratio of secondary metabolites between the root and the flour was 5.7 ( $P$ value $=0.0014)$, between the root and the roasted grains $2.2(P$ value $=0.0002)$, and between the flour and the roasted grains $2.6(P$ value $=0.0021)$. The drying of roots increases the levels of metabolites, most likely due to the release of the bound forms, while roasting tends to degrade all molecules. Supplementary work is being conducted on the presence of the conjugated and free forms of the metabolites of interest. The study of the process effects on the content of secondary metabolites related to the organoleptic characteristics of the various products is also in progress.

\section{Conclusion}

Our work has shown that the ternary mixture $\mathrm{H}_{2} \mathrm{O} / \mathrm{CHCl}_{3}$ / $\mathrm{MeOH}(30 / 30 / 40, \mathrm{v} / \mathrm{v} / \mathrm{v})$ can be used to extract the content of chlorogenic acids and sesquiterpene lactones of chicory root and its main food derivatives, flour, and roasted grains, simultaneously, with a higher efficiency than aqueous alcohol systems and a strong representation of the molecules. Direct extraction of the material, without an intermediate fractionation step (liquid-liquid extraction, SPE), evaporation, or resolubilization, followed by a short and simple chromatographic analysis, is a flexible, fast, and effective method. The chromatographic method profiled eight molecules belonging to families of major soluble secondary metabolites of chicory plant and is conducted with one extraction and one analysis. This method of simultaneous determination allows for comparative studies (physiological, genetic, or influencing the process) among the many products derived from chicory.

This targeted approach is currently being evaluated with a more comprehensive approach in which different mixtures tested to achieve this optimal system, including water/ chloroform/methanol solutions at $20 / 20 / 60$ or $30 / 30 / 40(\mathrm{v} /$ $\mathrm{v} / \mathrm{v}$ ), are combined with methodologies developed for the analysis of plant metabolomics [30]. These studies suggest 
the possibility of extending the metabolomics approach we have developed for chicory.

\section{Conflict of Interests}

The authors declare that there is no conflict of interests regarding the publication of this paper.

\section{Authors' Contribution}

Honorine Willeman designed and performed experiments, analyzed data, and wrote the paper. Philippe Hance conceived and conducted the study, designed experiments, and wrote the paper. Anne Fertin gave technical support and conceptual advice. Najia Voedts performed experiments. Nathalie Duhal performed experiments, analyzed data, and wrote the paper. Jean-François Goossens and Jean-Louis Hilbert revised critically the paper. Honorine Willeman and Philippe Hance contributed equally to this work.

\section{Acknowledgments}

The present work was financed by a public-private partnership, "Groupement d'intérêt Scientifique" GENOCHIC, involving UMR 1281 SADV, Université Lille 1, FlorimondDesprez Veuve et Fils SAS, and Leroux SAS. Funding was also provided by BPI France and the Région Nord Pas-de-Calais to QUALICHIC and GLYCACHIC projects. This work is supported by a doctoral fellowship from Leroux-Finaler SAS and the Doctoral School 104 SMRE to Honorine Willeman. The authors would like to thank Myriam Janssens, Grégoire Volpoet (Leroux-Finaler), and Nicolas Henry (FlorimondDesprez) for providing chicory root materials. The authors also acknowledge the team of the pole "Nutrition, Santé et Longévité" and especially Guillaume Orgeval for their helpful support in the realization of this project and the IRENI Institute for funds dedicated to the UPLC-High Resolution MS apparatus.

\section{References}

[1] S. B. Rees and J. B. Harborne, "The role of sesquiterpene lactones and phenolics in the chemical defence of the chicory plant," Phytochemistry, vol. 24, no. 10, pp. 2225-2231, 1985.

[2] J. R. Hagler and S. L. Buchmann, "Honey Bee (Hymenoptera: Apidae) foraging responses to phenolic-rich nectars," Journal of the Kansas Entomological Society, vol. 66, no. 2, pp. 223-230, 1993.

[3] G.-I. Arimura, S. Garms, M. Maffei et al., "Herbivore-induced terpenoid emission in Medicago truncatula: concerted action of jasmonate, ethylene and calcium signaling," Planta, vol. 227, no. 2, pp. 453-464, 2008.

[4] R. Niggeweg, A. J. Michael, and C. Martin, "Engineering plants with increased levels of the antioxidant chlorogenic acid," Nature Biotechnology, vol. 22, no. 6, pp. 746-754, 2004.

[5] Q. Wang and J. Cui, "Perspectives and utilization technologies of chicory (Cichorium intybus L.): a review," African Journal of Biotechnology, vol. 10, no. 11, pp. 1966-1977, 2011.
[6] C. Cavin, M. Delannoy, A. Malnoe et al., "Inhibition of the expression and activity of cyclooxygenase-2 by chicory extract," Biochemical and Biophysical Research Communications, vol. 327, no. 3, pp. 742-749, 2005.

[7] A. Wesołowska, A. Nikiforuk, K. Michalska, W. Kisiel, and E. Chojnacka-Wójcik, "Analgesic and sedative activities of lactucin and some lactucin-like guaianolides in mice," Journal of Ethnopharmacology, vol. 107, no. 2, pp. 254-258, 2006.

[8] M.-Y. Kim, K. Iwai, and H. Matsue, "Phenolic compositions of Viburnum dilatatum Thunb. fruits and their antiradical properties," Journal of Food Composition and Analysis, vol. 18, no. 8, pp. 789-802, 2005.

[9] D. Fraisse, C. Felgines, O. Texier, and J. L. Lamaison, "Caffeoyl derivatives: major antioxidant compounds of some wild herbs of the Asteraceae family," Food and Nutrition Sciences, vol. 2, pp. 181-192, 2011.

[10] K. R. Price, M. S. DuPont, R. Shepherd, H. W.-S. Chan, and G. R. Fenwick, "Relationship between the chemical and sensory properties of exotic salad crops-Coloured lettuce (Lactuca sativa) and chicory (Cichorium intybus)," Journal of the Science of Food and Agriculture, vol. 53, pp. 185-192, 1990.

[11] T. A. van Beek, P. Maas, B. M. King, E. Leclercq, A. G. J. Voragen, and A. de Groot, "Bitter sesquiterpene lactones from chicory roots," Journal of Agricultural and Food Chemistry, vol. 38, no. 4, pp. 1035-1038, 1990.

[12] C. Carazzone, D. Mascherpa, G. Gazzani, and A. Papetti, "Identification of phenolic constituents in red chicory salads (Cichorium intybus) by high-performance liquid chromatography with diode array detection and electrospray ionisation tandem mass spectrometry," Food Chemistry, vol. 138, no. 2-3, pp. 1062-1071, 2013.

[13] J. G. Foster, K. A. Cassida, and M. A. Sanderson, "Seasonal variation in sesquiterpene lactone concentration and composition of forage chicory (Cichorium intybus L.) cultivars," Grass and Forage Science, vol. 66, no. 3, pp. 424-433, 2011.

[14] A. M. Peters and A. van Amerongen, "Sesquiterpene lactones in chicory (Cichorium intybus L.): distribution in chicons and effect of storage," Food Research International, vol. 29, no. 5-6, pp. 439-444, 1996.

[15] M. N. Clifford, S. Shutler, G. A. Thomas, and O. Ohiokpehai, "The chlorogenic acids content of coffee substitutes," Food Chemistry, vol. 24, no. 2, pp. 99-107, 1987.

[16] H. Haffke and U. H. Engelhardt, "Chlorogensänren in KaffeeErsatzstoffen," Zeitschrift für Lebensmittel-Untersuchung und Forschung, vol. 183, no. 1, pp. 45-46, 1986.

[17] N. Mulinacci, M. Innocenti, S. Gallori, A. Romani, G. La Marca, and F. F. Vincieri, "Optimization of the chromatographic determination of polyphenols in the aerial parts of Cichorium intybus L.," Chromatographia, vol. 54, no. 7-8, pp. 455-461, 2001.

[18] F. Ferioli and L. F. D’Antuono, "An update procedure for an effective and simultaneous extraction of sesquiterpene lactones and phenolics from chicory," Food Chemistry, vol. 135, no. 1, pp. 243-250, 2012.

[19] P. Hance, Y. Martin, J. Vasseur, J.-L. Hilbert, and F. Trotin, "Quantification of chicory root bitterness by an ELISA for 11 $\beta$,13-dihydrolactucin," Food Chemistry, vol. 105, no. 2, pp. 742$748,2007$.

[20] R. Ihaka and R. Gentleman, "R: a language for data analysis and graphics," Journal of Computational and Graphical Statistics, vol. 5, no. 3, pp. 299-314, 1996. 
[21] Molinspiration, Calculation of molecular properties and bioactivity score, 2013, http://www.molinspiration.com/cgi-bin/ properties.

[22] R. Llorach, A. Martínez-Sánchez, F. A. Tomás-Barberán, M. I. Gil, and F. Ferreres, "Characterisation of polyphenols and antioxidant properties of five lettuce varieties and escarole," Food Chemistry, vol. 108, no. 3, pp. 1028-1038, 2008.

[23] Burdick and Jackson Laboratories, Solvent Guide, Burdick and Jackson Laboratories, Muskegon, Mich, USA, 2nd edition, 1980.

[24] S. Song, W. Zhou, Z. Liang et al., "The effect of methanol and ethanol cross-over on the performance of PtRu/C-based anode DAFCs," Applied Catalysis B: Environmental, vol. 55, no. 1, pp. 65-72, 2005.

[25] J. A. Elliott, S. Hanna, A. M. S. Elliott, and G. E. Cooley, “The swelling behaviour of perfluorinated ionomer membranes in ethanol/water mixtures," Polymer, vol. 42, no. 5, pp. 2251-2253, 2001.

[26] L. L. Burianek and A. E. Yousef, "Solvent extraction of bacteriocins from liquid cultures," Letters in Applied Microbiology, vol. 31, no. 3, pp. 193-197, 2000.

[27] M. Bahri, P. Hance, S. Grec et al., "A "novel" protocol for the analysis of hydroxycinnamic acids in leaf tissue of chicory (Cichorium intybus, L., Asteraceae)," The Scientific World Journal, vol. 2012, Article ID 142983, 8 pages, 2012.

[28] G. Guiochon and F. Gritti, "Shell particles, trials, tribulations and triumphs," Journal of Chromatography A, vol. 1218, no. 15, pp. 1915-1938, 2011.

[29] S. Fekete, K. Ganzler, and J. Fekete, "Efficiency of the new sub$2 \mu \mathrm{m}$ core-shell (Kinetex) column in practice, applied for small and large molecule separation," Journal of Pharmaceutical and Biomedical Analysis, vol. 54, no. 3, pp. 482-490, 2011.

[30] M. Gromova and C. Roby, "Toward Arabidopsis thaliana hydrophilic metabolome: assessment of extraction methods and quantitative 1H NMR," Physiologia Plantarum, vol. 140, no. 2, pp. 111-127, 2010. 

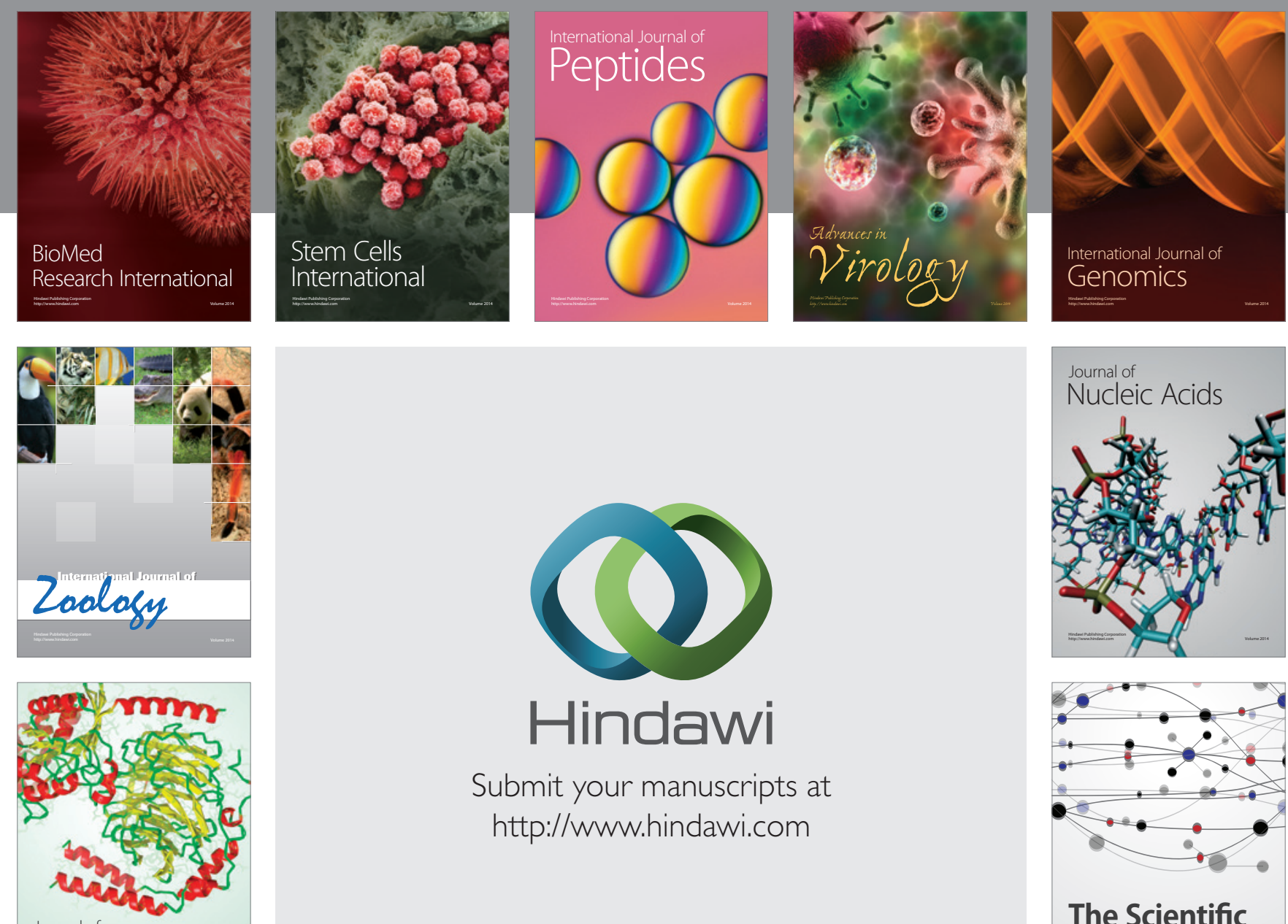

Submit your manuscripts at

http://www.hindawi.com

Journal of
Signal Transduction
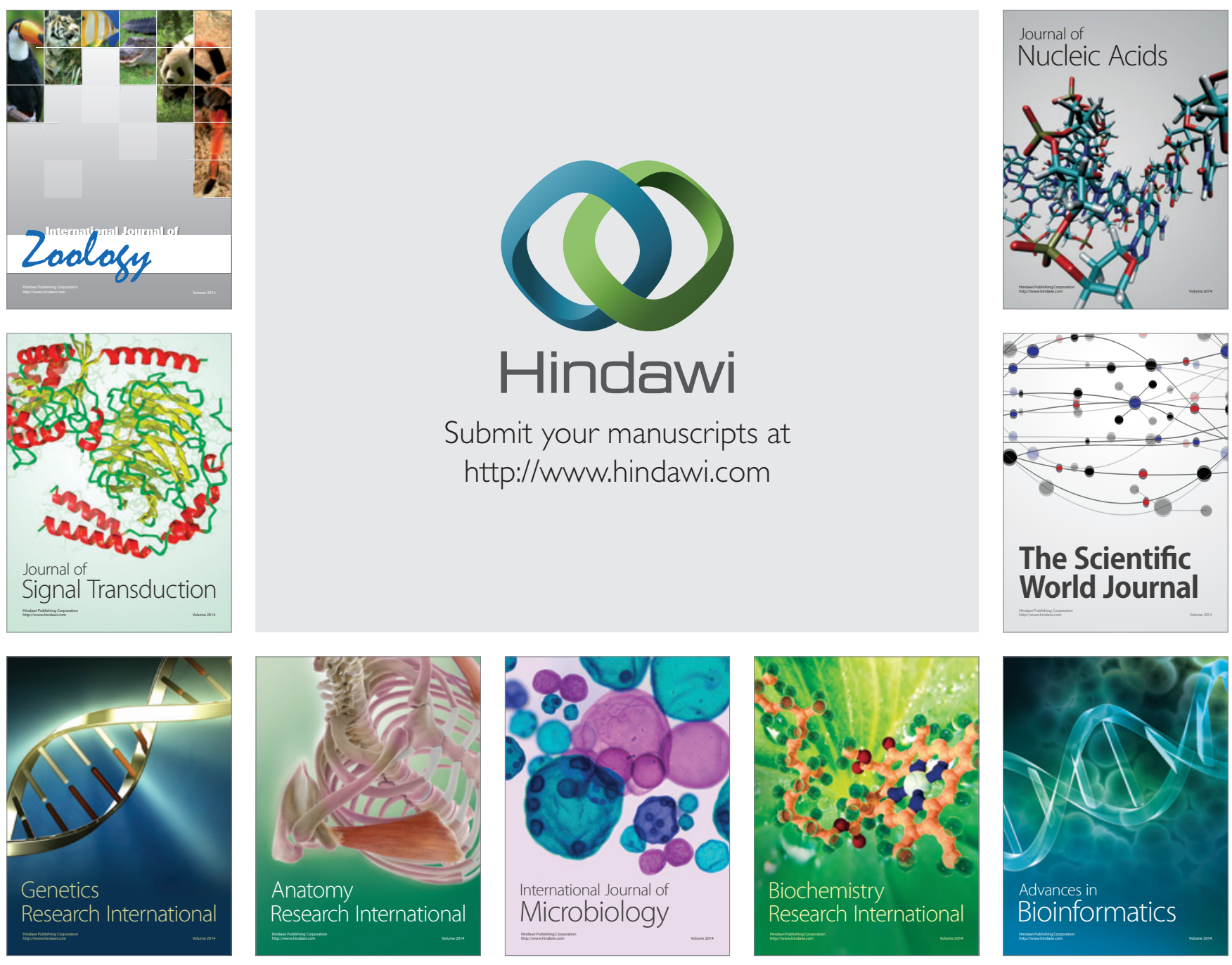

The Scientific World Journal
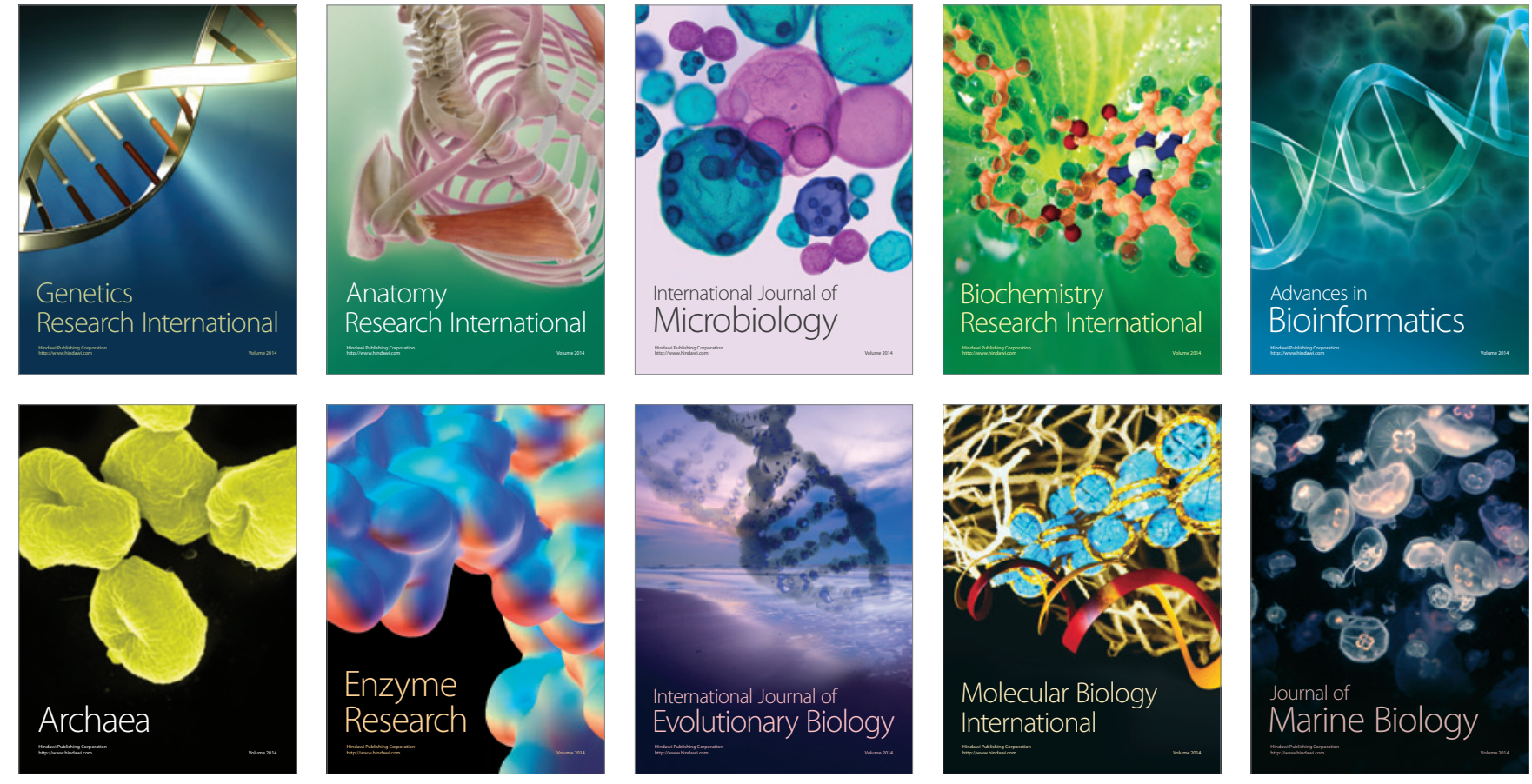